\title{
Pulmonary nocardiosis in a 3-year-old child
}

\author{
M. D. HOLDAW A Y, J K K N NEDY, T. ASHCROFT, AND \\ J . J . K A Y - B U T LE R
}

From the Royal Victoria Infirmary and the University of Newcastle upon Tyne

\begin{abstract}
Until 1960, 179 cases of infection with Nocardia asteroides had been described in the world literature. Seventeen cases in children were reported by 1963 . The organism is a common saprophyte in nature with probably a world-wide distribution. Infection can be primary but is more common in patients with underlying malignancy, auto-immune disease or preceding tuberculosis. Sulphonamides, particularly sulphadiazine, are the drugs of choice in treatment; the value of antibiotics is less clearly established. The indications for surgical treatment have not yet been defined. We record a further case of primary pulmonary nocardiosis in a 3-year-old child.
\end{abstract}

Infection with Nocardia asteroides was first described in cattle in Guadeloupe by Nocard (1888). The disease, locally known as farcy, superficially resembled actinomycosis but differed in that the organism grew aerobically. This infection was characterized by the occurrence of multiple abscesses and draining sinuses, pulmonary involvement, and emaciation leading to death. More recently the organism has been isolated from goats, horses, and dogs as well as being a common saprophyte in soils (Wilson and Miles, 1964).

Eppinger (1890) described what is believed to be the first human case, two years after Nocard's isolation of the organism. Over the next 25 years, 22 human cases were reported in the literature, 15 of them from Europe (Hunter, Willcox, and Woolf, 1954). Murray, Finegold, Froman, and Will (1961) reported 179 cases in the world literature to 1960, most coming from the United States.

Reports of cases of pulmonary nocardiosis have appeared only twice in the British literature over the last 60 years. Foulerton, in the Milroy Lectures (1910), described several examples of infection with an organism which he called a streptothrix, and two of these cases were probably examples of pulmonary nocardiosis. Hunter et al. (1954) described a 50-year-old woman with exfoliative dermatitis who developed pulmonary nocardiosis with lesions resembling miliary tuberculosis.

By 1963, 17 cases of Nocardia asteroides infection had been reported in children (Carlile, Holley, and Logan, 1963). Nine of these patients had pulmonary involvement, two of whom

${ }^{1}$ Present address : Doncaster Royal Infirmary, Doncaster recovered; the outcome in a further two is unknown. The other children had infection at various sites, including the peritoneum, gastrointestinal tract, liver, spleen, knee joint, calf muscles, and the brain.

We wish to report a further case which occurred in a young child.

\section{CASE REPORT}

INITIAL ILLNESS AND INVESTIGATIONS The patient was

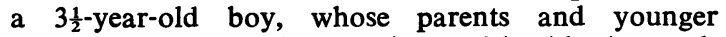
brother aged 4 months were in good health. A grandfather owned a small farm which the family visited at week-ends, but the boy had little contact with animals. In the past he had been well apart from minor respiratory infections, the last being a mild attack of pharyngitis three months before the onset of this illness.

He was admitted to hospital in September 1964 with a 12-day history of anorexia, listlessness, and intermittent fever. An initial diagnosis of tonsillitis had been made by the family doctor and $2.5 \mathrm{~g}$. of phenoxymethylpenicillin had been given for five days: he had improved at first but did not return to normal.

On admission he was drowsy, with an axillary temperature of $103.5^{\circ} \mathrm{F}$. Respirations were rapid and shallow (60 per minute) and there was clinical evidence of consolidation in the upper and lower lobes of the right lung. The spleen was just palpable and several small lymph nodes were felt in the neck and axillae.

The blood picture at this time showed $\mathrm{Hb} 10.8 \mathrm{~g} . /$ 100 ml., white blood count 26,000/c.mm., $76 \%$ neutrophils, $20 \%$ lymphocytes, and $4 \%$ monocytes. Chest radiographs showed consolidation in the posterior basal segment of the right lower lobe, a round opacity in the upper lobe, and a small basal 


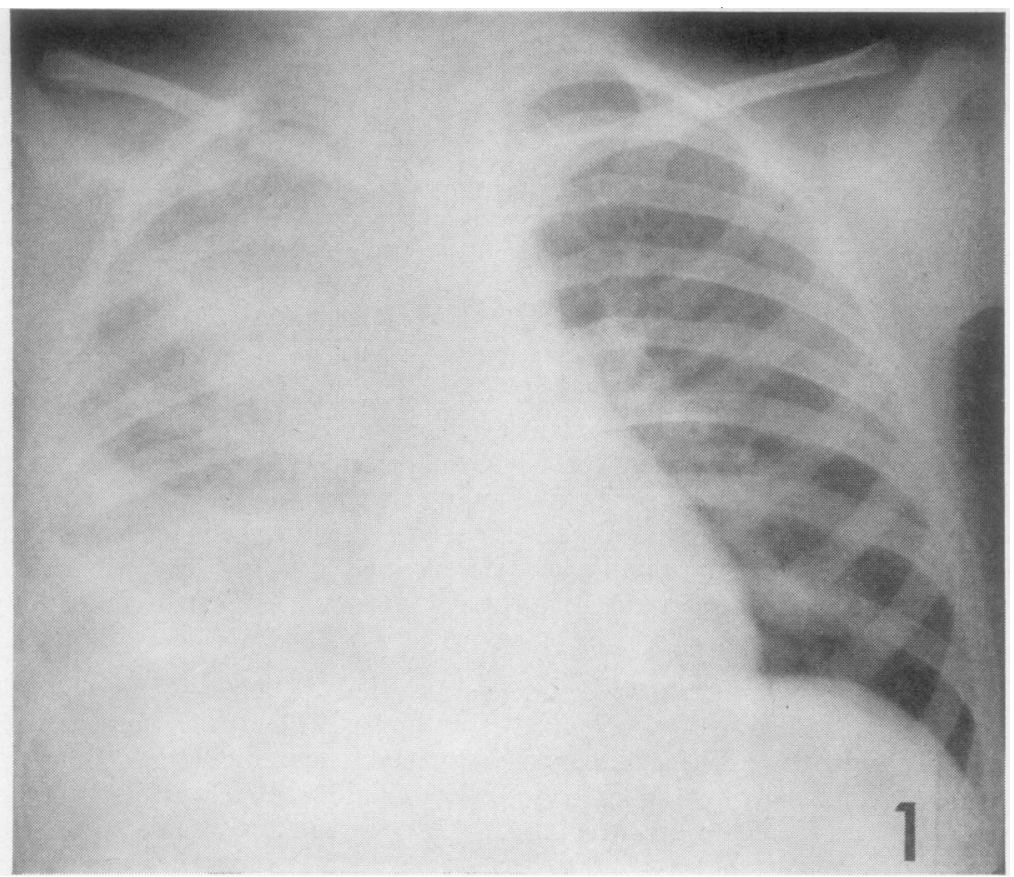

FIG. 1. (14.9.64) P.A. view shows a circular area of consolidation in the right upper zone and consolidation and effusion at the right base.

effusion which extended forwards and upwards into the oblique fissure. The left lung and heart were normal (Fig. 1). A Mantoux test with 10 units of tuberculin (P.P.D.) became positive, with a $10 \mathrm{~mm}$. weal, within 48 hours but had faded 48 hours later. The child had not had B.C.G. The urine was normal. Serum protein content was $5.8 \mathrm{~g} . / 100 \mathrm{ml}$., with a rise in $\alpha 2$ globulin shown on electrophoresis. Subsequent analysis of blood taken during the height of the illness showed a total $\gamma$-globulin of $1.6 \mathrm{~g} . / 100 \mathrm{ml}$., $\gamma$-macroglobulin and $\gamma \mathrm{A}$ being $400 \%$ and $150 \%$ respectively of the levels in a standard normal serum. These are remarkably high values for a child of this age.

BACTERIOLOGY The effusion was aspirated and $8 \mathrm{ml}$. of grey-green pus was obtained. A Gram-positive filamentous organism was seen in the direct film of the pleural fluid. It showed true branching and was acid-fast by a modified Ziehl-Nielsen method using $5 \%$ sulphuric acid. It grew aerobically at $37^{\circ} \mathrm{C}$. on blood agar as small, hard, irregular colonies; it did not grow anaerobically. In nutrient broth it grew slowly, producing a granular deposit, a film of this showing bacillary and coccal forms. A deeply pigmented orange-yellow growth was obtained on a potato slope after 10 days' incubation. The following carbohydrates in peptone water were not fermented: arabinose, ribose, trehalose, rhamnose, galactose, adonitol, and sorbitol. Gelatin was not liquefied.

Intraperitoneal inoculation of a guinea-pig with a음 broth culture of the organism isolated from the pleural fluid resulted in the death of the animal in $\delta$ nine days. At necropsy the animal was wasted, the 3 omentum was matted, and the diaphragm was studdedi with small white nodules. Numerous abscesses were present in the liver, spleen, kidneys, and lungs. They showed a central area occupied by polymorphs and윽 necrotic tissue and a peripheral zone containing $D$ numerous histiocytes with the formation of multi-을 nucleated giant cells. Gram-positive and partially acid-fast filamentous bacilli were demonstrated in the smears and slides prepared from the affected tissues. N Culture of the material yielded a pure growth of then original organism.

On the basis of these findings the organism was identified as Nocardia asteroides. Tubercle bacille were never seen in any of the specimens from the $\mathbb{D}$ patient nor grown in numerous cultures.

Antibiotic sensitivity tests were carried out by the disc method with the results shown in the Table.

By a tube method penicillin was ineffective at concentrations up to 60 units per $\mathrm{ml}$. but exhibited some inhibitory activity at higher concentrations. By a similar method diphenylsulphone (Dapsone) showed activity, but owing to the very low water solubility of 
T A B L E

ANTIBIOTIC SENSITIVITY TESTS

\begin{tabular}{|c|c|}
\hline & Disc Concentration $(\mu \mathrm{g})$. \\
\hline $\begin{array}{l}\text { Fully sensitive to: } \\
\text { Streptomycin }\end{array}$ & 10 \\
\hline $\begin{array}{l}\text { Partially sensitive to: } \\
\text { Sulphonamide group }\end{array}$ & 100 \\
\hline $\left.\begin{array}{l}\text { Resistant to: } \\
\text { Isoniazid } \\
\text { Demethylchlortetracycline } \\
\text { Cephaloridine } \\
\text { Lincomycin } \\
\text { Cloxacillin } \\
\text { Ampicillin } \\
\text { Fusidic acid } \\
\text { Kanamycin } \\
\text { Cephalosporin } \\
\text { Para-amino-salicylic acid } \\
\text { Polymyxin } \\
\text { Chloramphenicol } \\
\text { Erythromycin } \\
\text { Novobiocin } \\
\text { Neomycin } \\
\text { Framycetin } \\
\text { Amphotericin } \\
\text { Cycloserine } \\
\text { Ethionamide } \\
\text { Thiacetazone } \\
\text { Hydroxystilbamidine isothionate }\end{array}\right\}$ & $\begin{array}{r}1 \\
2 \\
2 \\
2 \\
4 \\
5 \\
5 \\
5 \\
5 \\
5 \\
20\end{array}$ \\
\hline
\end{tabular}

this drug (1 part in 7,000) it was not possible to establish an exact inhibitory concentration.

MANAGEMENT AND PROGRESS We suspected an unusual condition but decided to treat with benzylpenicillin, 2 million units intramuscularly, and sulphadimidine, 2 g. by mouth, in each 24 hours. The child's condition deteriorated rapidly and within two days he had become cyanosed and very ill. With the appearance of a positive tuberculin reaction streptomycin, $0.6 \mathrm{~g}$., and isoniazid, $300 \mathrm{mg}$., daily were added. He became irritable and semi-comatose, but the cerebrospinal fluid was normal. By the fifth day there was some general improvement but the liver was enlarging. Tests of liver function (plasma bilirubin total $0.1 \mathrm{mg} . / 100 \mathrm{ml}$., zinc sulphate 3 units, thymol turbidity 2 units, thymol flocculation + , cephalin cholesterol 0 , alkaline phosphatase 16 K.A. units) were normal for a child of his age apart from a rise in the serum aspartate aminotransferase (S.G.O.T.) to 55 units. A further chest radiograph showed cavitation in the right upper lobe (Fig. 2). The empyema was aspirated twice more ; culture of the thick pus obtained once again showed Nocardia asteroides. No other organism was grown.

On the eighth day, when Nocardia asteroides had been identified and in vitro sensitivities determined, penicillin and isoniazid were discontinued, and therapy was maintained with sulphadimidine and streptomycin.

On the fourteenth day, in view of experience in other cases (Hathaway and Mason, 1962), sulphadiazine, $4 \mathrm{~g}$. daily, with added sodium citrate was substituted for sulphadimidine.

During the second and third weeks there was gradual general improvement, but there was clinical and radiological evidence of an enlarging abscess in the right upper lobe, spreading infection in the right lower lobe, and a persisting empyema. Patchy shadows were visible in the left lung (Fig. 3). Surgical drainage was considered but rejected because of the poor general condition and from fear of fistula formation as seen in actinomycosis.

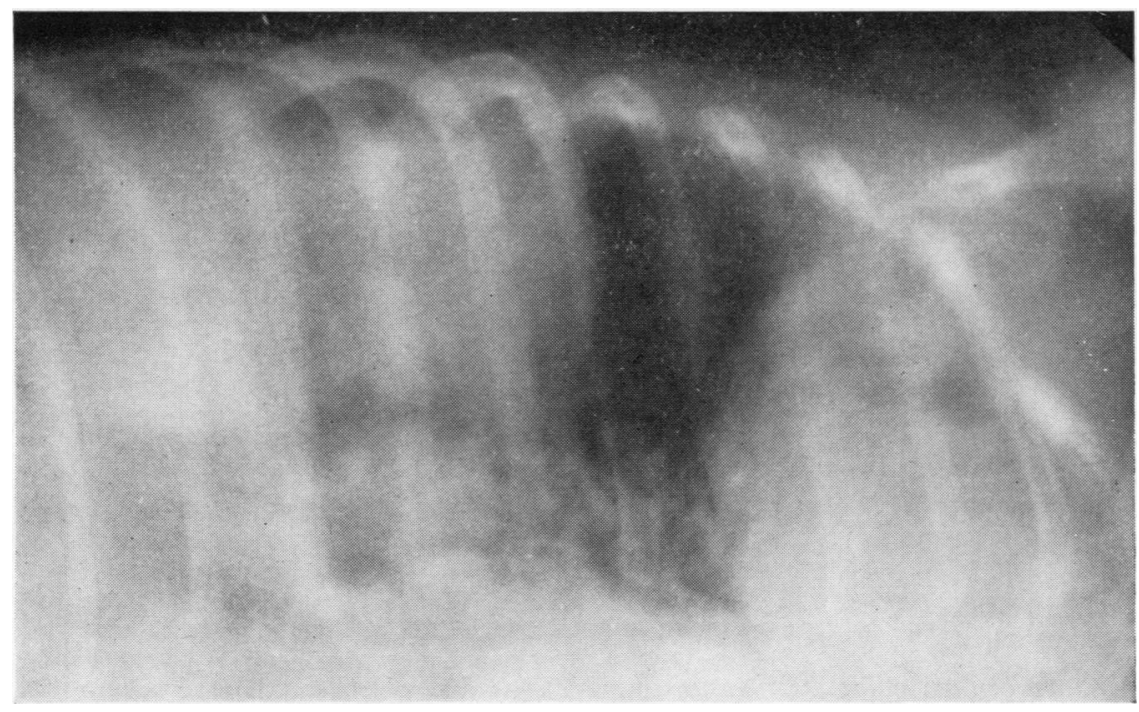

FIG. 2. (23.9.64) Lateral decubitus view of right side of thorax shows cavitating lesions in the right upper zone with fluid levels and a fluid level in the right costophrenic sulcus. 
By the fiith week of the illness, three weeks from starting streptomycin and sulphonamides, cultures of the aspirated pus were sterile, but a fortnight later a small fluctuant swelling developed over the right temporal bone. There was no change in the underlying bone radiologically and the aspirated pus was sterile.

Three months from the onset of the illness bronchoscopy was carried out. Thick yellow pus was seen in the right main bronchus, coming from the upper lobe and the medial basal segment of the lower lobe. The bronchial mucosa was intact and no foreign body was seen. Five millilitres of 'cheesy' material was aspirated from the abscess in the right upper lobe with a large-bore needle and syringe, but this material and the bronchial aspirate were sterile.

Following the bronchoscopy there was a sharp deterioration in the child's condition, with a return of high fever and cyanosis. Benzylpenicillin, 4 million units daily intravenously, and probenecid, $150 \mathrm{mg}$. six-hourly, were added to the streptomycin and sulphadiazine. After three weeks there was no improvement and they were discontinued. The boy was pale and wasted, finger clubbing had developed, and he required repeated blood transfusions. As diphenylsulphone was known to be effective in infections with Nocardia braziliensis, this drug (25 mg. daily) was substituted for streptomycin.
During the fourth and fifth months of the disease he remained very ill. Pus cells and red cells appeared in the urine intermittently, but cultures were sterile and no crystalluria was found. He was now a respiratory cripple, requiring an oxygen tent throughout the night and periodically during the day, yet his morale was maintained and he was alert and active. Radiologically there was a steady increase in the size of the upper lobe abscess with the formation of a pyopneumothorax (Fig. 4). Serological studies showed a weak reaction to Aspergillus fumigatus, but no precipitins against extracts of Nocardia asteroides were demonstrated.

At this point we felt that the Nocardia infection had been controlled and that the child's continuing ill health and respiratory difficulty were due to displacement of the mediastinum to the left by the large abscesses in the right lung. He was transferred to a thoracic surgery unit and the abscess on the right was drained after resection of the sixth rib. The thick yellow pus obtained produced a moderate growth of Proteus vulgaris, but Nocardia was not isolated. Subsequent cultures from the drainage site grew Escherichia coli at first and 14 days later coagulase-positive staphylococci. Despite the development of a bronchial fistula his condition improved initially but deteriorated rapidly following the onset of staphylococcal infection even though he was given 




FIG. 4. (20.2.65) P.A. view shows a large pyopneumothorax on the right with thickening of the pleura. The nodular shadows on the left are more marked and there is a suspicion of cavitation in two areas.

methicillin. He died 36 days after drainage-that is, seven months from the beginning of the illness.

NECROPSY The body was extremely emaciated. The upper lobe of the right lung was mostly replaced by an irregular cavity, measuring $9 \times 6 \times 5 \mathrm{~cm}$., into which several small bronchi opened. The cavity contained creamy, friable material and drained laterally on to the skin through a sinus in the bed of the sixth rib. This cavity extended into the anterior mediastinum, where it occupied the site of the thymus. Two further irregular cavities were found in the middle and lower lobes $(5 \mathrm{~cm}$. and $7 \mathrm{~cm}$. in diameter) filled with yellowish-grey 'caseous' material. The intervening lung tissues contained numerous small lesions ( 1 to $5 \mathrm{~mm}$. in diameter) of similar appearance, and some were also present in the hilar lymph nodes. The left lung was studded with similar lesions, mostly small but with one $3 \mathrm{~cm}$. in diameter.

Both pleural cavities were obliterated by fibrous adhesions. The parietal pericardium was thickened on the right side and was studded with typical lesions up to $1 \mathrm{~cm}$. in diameter, but the cavity was not involved.

Necrotic lesions, ranging from $3 \mathrm{~mm}$. to $2 \mathrm{~cm}$. in diameter, were present in the liver, in the lower pole of the right kidney, around the pelvis of the left kidney, in the thickened splenic capsule, the right temporalis muscle, and in lymph nodes in the mesentery and the neck.

The brain, meninges, gastro-intestinal tract, endocrine glands, and genital system showed no significant changes.
MICROSCOPIC APPEARANCES The larger lesions in the lungs and all those in other organs showed similar features. A large central area of caseation necrosis was surrounded by a thin rim of cellular tissue containing fibroblasts, lymphocytes, and histiocytes, with occasional multinucleated giant cells of Langhans type and a few polymorphs and plasma cells. This in turn was surrounded by a narrow capsule of mature fibrous tissue outside which lymphocytes were scattered in the tissues. Both lungs also contained many miliary lesions consisting of a small nodule of cellular fibrous tissue, showing central necrosis in some cases, with a sparse accumulation of lymphocytes and the formation of occasional Langhans type giant cells. The appearances in the miliary lesions suggested a quiescent or healing phase of the disease. In other areas the pulmonary alveoli contained scattered polymorphs and macrophages. Sections stained by ZiehlNielsen, Gram, and PAS methods revealed no organisms.

An added feature in the wall of the large cavity occupying the right upper lobe was extensive nonspecific acute inflammatory change, suggesting secondary pyogenic infection, an impression supported by the culture of Staphylococcus aureus from its contents.

\section{DISCUSSION}

There is no doubt that this child had primary nocardiosis. He died from a combination of chronic pulmonary inflammation and destruction, respiratory insufficiency, and terminal infection 
with Staphylococcus aureus. Nocardia asteroides was never isolated from his urine, nor was it cultured from any specimen of pus after the third week. Since there was little difficulty in isolating the organism originally, it is unlikely that this was due to a failure in technique. Post-mortem specimens failed to produce Nocardia in culture ; moreover the histological sections suggested healing in some places.

THE ORGANISM The presence of a Gram-positive, partially acid-fast organism showing true branching is indicative of the genus Actinomyces or Nocardia. Aerobic growth excludes the former. The characteristics of the organism have already been described. Provided a Gram film is made of the specimen, the organism is unlikely to be 'missed'. The organism is slow-growing, so that cultures must be kept for at least 10 or 12 days before being discarded.

Guinea-pig inoculation confirms the diagnosis since Nocardia asteroides is the only member of the genus pathogenic to laboratory animals.

THE LESIONS The lesions found in this child's lungs, liver, lymph nodes, and muscles were characterized by a central area of caseous necrosis surrounded by a granulomatous reaction with Langhans giant cells. Fibrous reaction was notably sparse. These lesions resemble those seen in caseous tuberculosis, but tubercle bacilli were neither seen histologically nor cultured despite repeated attempts. Similar granulomatous reactions were seen in the tissues of the guinea-pig. Murray et al. (1961) described similar histological changes in the tissues of their cases. Only in the abscess in the upper lobe of the right lung was there any evidence of an acute inflammatory reaction: Staph. aureus was isolated from this site at necropsy and was probably a terminal addition to the picture.

CLINICAL ASPECTS Nocardia asteroides is a common saprophyte in nature and can be isolated from soil, decaying organic matter, grasses, and straw. Webster (1962) reported a particularly high incidence in farmers, and he queries the possibility of air-borne contamination. Spread from man to man has not been reported. This child did visit a farm regularly, but there was no overt disease among the cattle.

We found no evidence of a precipitating cause. He had been in good health previously and had no anatomical abnormality of the lungs, inhaled foreign body, underlying malignant disease, or deficiency in the production of immune globulins as Murray et al. (1961) found in many of their cases.

The onset of the illness was gradual at first and the child was thought to be suffering from a minor upper respiratory infection. On the twelfth day he abruptly became very ill ; the disease then progressed relentlessly to massive destruction of the right lung, with gross impairment of respiratory function. Some cases previously reported in the literature have had acute suppurative infections and others more chronic granulomatous lesions (Murray et al., 1961), while pulmonary nocardiosis in children has usually been rapidly fatal (Carlile et al., 1963). A striking feature was the transient reaction to 10 units of tuberculin PPD. Ballenger and Goldring (1957) found a positive tuberculin reaction in guinea-pigs with nocardiosis, but Drake and Henrici (1943) were unable to find any such relationship.

The radiographic changes in this case were those of multiple abscesses in the right lung with a small empyema and lobular pneumonic lesions on the left. Radiographic changes in previous reports have been variable. The woman described by Hunter et al. (1954) was thought to be suffering from miliary tuberculosis. Other cases have shown peribronchial lymphadenitis or chronic suppuration with a honeycomb appearance in the lung (Webster, 1962).

Spread to other organs is common, particularly in the central nervous system. Murray et al. (1961) describe spread to the central nervous system from the lungs in $7 \%$ of cases and disseminated disease in several organs, including the brain, in $30 \%$. The present case had no involvement of the brain or meninges but did show dissemination to the liver, kidneys, muscle, and widely distributed lymph nodes, as well as locally to the pleural cavity and outer surface of the pericardium.

MANAGEMENT Throughout his illness the child O was treated with sulphonamides in high dosage as $N$ well as several antibiotics. Runyon (1951) stressed $\underset{\omega}{N}$ the importance of sulphonamides in treatment, and 0 this has been confirmed by other authors (Murray et al., 1961 ; Freese, Young, Sealy, and Conant, $\frac{\mathrm{C}}{\mathrm{C}}$ 1963). Hathaway and Mason (1962) suggested that $\stackrel{\mathcal{\infty}}{+}$ there may be some advantage in giving sulpha- 0 diazine rather than other sulphonamides. The part $\bar{O}$ played by antibiotics is less clear. The in vitro sensitivities can be misleading in treatment. Unlike $\mathbb{\otimes}$ Actinomyces, Nocardia is almost invariably resistant to penicillin, while streptomycin, erythromycin, novobiocin, and chloramphenicol have 
been reported to be effective in some patients (Hathaway and Mason, 1962 ; Larsen, Diamond, and Collins, 1959). Seabury and Dascomb (1964) were unable to show any definite effect with amphotericin $B$ and advocate sulphadiazine and cycloserine in the initial treatment of nocardiosis.

The place of surgery is in doubt. None of Webster's (1962) 10 cases underwent surgery and yet nine recovered. In the 11 cases described by Freese and his colleagues, thoracotomy was performed only in three whose lesions were thought to be tuberculous. Brine (1965) advocates early complete excision of the focus as well as the institution of long-term sulphadiazine therapy. We have naturally wondered whether this would have been the right course in this child, but at a time when his general condition was very poor right pneumonectomy would almost certainly have proved fatal. Attempted drainage of the abscess in the upper lobe of the right lung at a later stage resulted in the rapid onset of secondary infection.

Although infection with Nocardia asteroides must be rare, its widespread distribution as a saprophyte in nature makes it seem likely that more cases may be recognized in the future. A higher incidence can be expected in patients suffering from malignant disease or any condition interfering with the immune defence mechanism. It has also been described as a concomitant infection in tuberculosis, and the similarity of the radiological and histological changes makes it seem likely that some cases may have been misdiagnosed.

We wish to thank Professor S. D. M. Court, Professor of Child Health in the University of Newcastle upon Tyne, for permission to report this case. We are also grateful to Mr. S. C. Griffin, Consultant Thoracic Surgeon, Newcastle upon Tyne, and Dr. J.
Heycock, Consultant Paediatrician, Sunderland, for their ready help in the child's care. Dr. F. L. Constable and Miss B. Leask, B.Sc., of the Department of Microbiology, Royal Victoria Infirmary, Newcastle upon Tyne, were both of great assistance in identifying the organism. Dr. J. F. Sjothill, London University Institute of Child Heath, kindly carried out the studies of the concentrations of the immunoglobulins, and Dr. J. Pepys, Institute of Diseases of the Chest London, performed the serological investigation for Nocardia asteroides. Finally, we should like to thank all those others who willingly gave us the benefit of their experience.

\section{REFERENCES}

Ballenger, C. N., and Goldring, D. (1957). Nocardiosis in childhood. J. Pediat., 50, 145.

Brine, J. A. S. (1965). Human nocardiosis: a developing clinical picture. Med. J. Aust., 1, 339.

Carlile, W. K., Holley, K. E., and Logan, G. B. (1963). Fatal acute disseminated nocardiosis in a child. J. Amer. med. Ass., 184, 477.

Drake, C. H., and Henrici, A. T. (1943). Nocardia asteroides: its pathogenicity and allergic properties. Amer. Rev. Tuberc., 48, 184.

Eppinger, H. (1890). Ueber eine neue pathogene Cladothrix und eine durch sie hervorgerufene Pseudotuberculosis. Beitr. path. Anat., 9, 287.

Foulerton, A. G. R. (1910). The Milroy Lectures on "The Strepto trichoses and Tuberculosis". Lancet, 1, 551, 626, 769.

Freese, J. W., Young, W. G., Sealy, W. C., and Conant, N. F. (1963) Pulmonary infection by Nocardia asteroides. J. thorac. cardiovas Surg., 46, 537.

Hathaway, B. M., and Mason, K. N. (1962). Nocardiosis; study of fourteen cases. Amer. J. Med., 32, 903.

Hunter, R. A., Willcox, D. R. C., and Woolf, A. L. (1954). Aerobic actinomycosis, with a report of a case resembling miliary tuberculosis. Guy's Hosp. Rep., 103, 196.

Larsen, M. C., Diamond, H. D., and Collins, H. S. (1959)."Nocardia asteroides infection. Arch. intern. Med., 103, 712.

Murray, J. F., Finegold, S. M., Froman, S., and Will, D. W. (1961). The changing spectrum of nocardiosis; a review and presentation of nine cases. Amer. Rev. resp. Dis., 83, 315.

Nocard, E. (1888). Note sur le maladie des boeufs de la Guadeloupe connue sous le nom de farcin. Ann. Inst. Pasteur, 2, 293.

Runyon, E. H. (1951). Nocardia asteroides: studies of its pathogenicity and drug sensitivities. J. Lab. clin. Med., 37, 713.

Seabury, J. H., and Dascomb, H. E. (1964). Results of the treatment of systemic mycoses. J. Amer. med. Ass., 188, 509.

Webster, B. H. (1962). Bronchopulmonary nocardiosis. Amer. J. med. $S c i ., 244,40$.

Wilson, G. S., and Miles, A. A. (1964). Topley and Wilson's Principles of Bacteriology and Immunity. 5th ed., vol. 1, p. 500. Arnold, London. 